\title{
Clinical Relevance of Cyclic GMP Modulators: A Translational Success Story of Network Pharmacology
}

Citation for published version (APA):

Oettrich, J. M., Dao, V. T., Frijhoff, J., Kleikers, P. W. M., Casas Guijarro, A., Hobbs, A. J., \& Schmidt, H. H. H. W. (2016). Clinical Relevance of Cyclic GMP Modulators: A Translational Success Story of Network Pharmacology. Clinical Pharmacology \& Therapeutics, 99(4), 360-362. https://doi.org/10.1002/cpt.336

Document status and date:

Published: 01/04/2016

DOI:

$10.1002 /$ cpt.336

Document Version:

Publisher's PDF, also known as Version of record

Document license:

Taverne

Please check the document version of this publication:

- A submitted manuscript is the version of the article upon submission and before peer-review. There can be important differences between the submitted version and the official published version of record.

People interested in the research are advised to contact the author for the final version of the publication, or visit the DOI to the publisher's website.

- The final author version and the galley proof are versions of the publication after peer review.

- The final published version features the final layout of the paper including the volume, issue and page numbers.

Link to publication

\footnotetext{
General rights rights.

- You may freely distribute the URL identifying the publication in the public portal. please follow below link for the End User Agreement:

www.umlib.nl/taverne-license

Take down policy

If you believe that this document breaches copyright please contact us at:

repository@maastrichtuniversity.nl

providing details and we will investigate your claim.
}

Copyright and moral rights for the publications made accessible in the public portal are retained by the authors and/or other copyright owners and it is a condition of accessing publications that users recognise and abide by the legal requirements associated with these

- Users may download and print one copy of any publication from the public portal for the purpose of private study or research.

- You may not further distribute the material or use it for any profit-making activity or commercial gain

If the publication is distributed under the terms of Article $25 \mathrm{fa}$ of the Dutch Copyright Act, indicated by the "Taverne" license above, 


\section{ASCPT Journals}

CPT: Pharmacometrics \& Systems Pharmacology (PSP) Impact Factor: 4.054

A timely, online-only, Open Access, cross-disciplinary journal devoted to publishing advances in quantitative methods as applied in pharmacology, physiology, and therapeutics in humans.

Clinical and Translational Science (CTS)

Impact Factor: 4.689

CTS Trincial and Iationa Science

Highlights original research that helps bridge laboratory discoveries with the diagnosis and treatment of human disease. An Open Access publication.

CPT: Pharmacometrics \& Systems Pharmacology

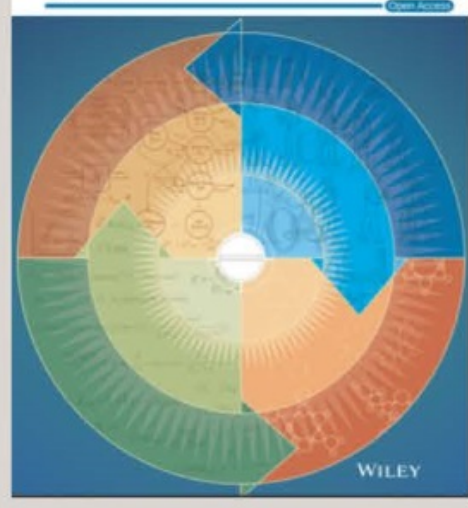

Clinical Pharmacology \& Therapeutics (CPT)

\section{Impact Factor: 6.875}

The authoritative cross-disciplinary journal in experimental and clinical medicine devoted to publishing advances in the nature, action, efficacy, and evaluation of therapeutics. 


\title{
Clinical Relevance of Cyclic GMP Modulators: A Translational Success Story of Network Pharmacology
}

\author{
JM Oettrich $^{1}$, VT Dao ${ }^{1}$, J Frijhoff ${ }^{1}$, PWM Kleikers ${ }^{1}$, AI Casas ${ }^{1}$, AJ Hobbs ${ }^{2}$ and HHHW Schmidt ${ }^{1}$
}

Therapies that modulate cyclic guanosine $-3^{\prime}-5^{\prime}$-monophosphate (cGMP) have emerged as one of the most successful areas in recent drug discovery and clinical pharmacology. Historically, their focus has been on cardiovascular disease phenotypes; however, cGMP's relevance is likely to go beyond this rather limited organ-based set of indications. Moreover, the multitude of targets and their apparent interchangeability is a proof-of-concept of network pharmacology.

The key components of the cGMP signaling network (Figure 1) include cGMP-producing guanylyl cyclases (GC), cGMPdegrading phosphodiesterases (PDE), and cGMP target proteins (kinases, ion channels, and cGMP-regulated phosphodiesterases). We here provide an overview of the associated drugs and their potentially confusing terminology as well as an up-to-date snapshot of their clinical development and/or therapeutic relevance. In the future, this will most likely also include combinations of different types of cGMP-modulating drugs to increase overall disease specificity and safety. Finally, these approaches are likely to be increasingly guided by innovative biomarker panels yielding powerful therapeutic/diagnostic (theranostic) couples for precision medicine.

\section{CYCLIC GMP AND ITS CLINICAL PHARMACOLOGICAL RELEVANCE}

Cyclic GMP signaling exerts an important protective influence within the vasculature by smooth muscle relaxation and inhibition of proliferation, fibrosis, and platelet aggregation. Cyclic GMP is synthesized from guanosine- $3^{\prime}, 5^{\prime}$-triphosphate (GTP) by soluble and particulate guanylyl cyclases, which function as receptors for nitric oxide (NO) and natriuretic peptides (NP), respectively. NO and NP signaling input is limited by oxidative stress and the metalloprotease neprilysin, which respectively hydrolyze NPs. NO- or NP-induced increases in cGMP activate cGMP- dependent protein kinases (PKG), cyclic nucleotide-gated ion channels, and both cAMP and cGMP-hydrolyzing phosphodiesterases (PDEs; cGMP can also inhibit some isoforms of the PDE enzyme family). In turn, this leads to altered phospho-protein patterns, a decrease in intracellular calcium levels and sensitivity, and altered cAMP/cGMP levels. Cyclic GMP signaling is also physiologically limited by phosphodiesterases (PDEs) that hydrolyze cGMP.

With respect to pathophysiology, mechanism-based dysregulation of cGMP signaling has been attributed to both reduced cGMP synthesis and/or enhanced cGMP breakdown. In this latter context, the underlying mechanisms include reduced levels of $\mathrm{NO},{ }^{1}$ damaged NO-sensitive $\mathrm{sGC},{ }^{2}$ and enhanced cGMP breakdown. In addition, and distinct from these mechanism-based alterations, cGMP modulating drugs have been employed in a symptom-based manner, i.e., without evidence of an underlying "cGMPopathy," in pulmonary hypertension ${ }^{3}$ and chronic kidney disease.

\section{THE NO-RECEPTOR, SOLUBLE GC (SGC)}

Soluble GC is a heterodimeric heme protein with two isoforms, $\alpha_{1} /$ $\beta_{1}$ or GC-1 and $\alpha_{2} / \beta_{1}$ or GC- 2 . Both consist of three principal functional domains: an $\mathrm{N}$-terminal $\mathrm{Fe}(\mathrm{II})$ heme-binding region that confers sensitivity to $\mathrm{NO}$, a C-terminal catalytic functionality, and a central dimerization region. Binding of $\mathrm{NO}$ to the histidine-ligated $\mathrm{Fe}(\mathrm{II})$ heme induces a structural conformation that activates the enzyme's catalytic site. Inappropriate reactive oxygen species formation, in particular superoxide, can interfere with NO-cGMP signaling in at least three ways: by chemically scavenging $\mathrm{NO}$; by uncoupling NO synthase (NOS); or by oxidizing sGC's Fe(II) to $\mathrm{Fe}(\mathrm{III})$ heme, resulting eventually in apo-sGC prone to proteasomal degradation. Recoupling NOS has been shown to be preclinically effective by supplying its redox sensitive cofactor, tetrahydrobiopterin, or L-arginine. Therapeutically, NO substitution with so-called

${ }^{1}$ Department of Pharmacology, Cardiovascular Research Institute Maastricht (CARIM), Maastricht University, Maastricht, The Netherlands; ${ }^{2}$ William Harvey Research Institute, Barts and The London School of Medicine and Dentistry, Queen Mary University of London, London, UK. Correspondence: HHHW Schmidt (H.Schmidt@maastrichtuniversity.nl). 


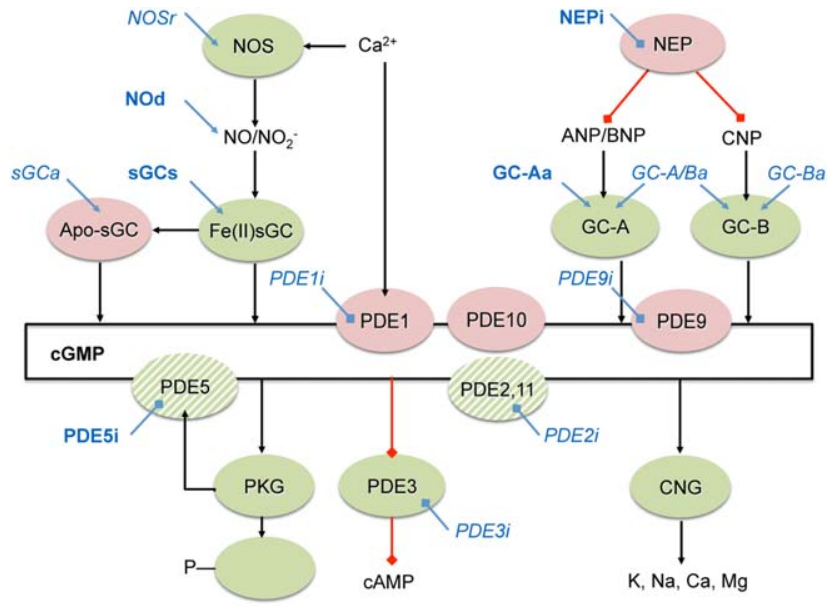

Figure 1 Schematic overview of the cGMP signaling pathway and its regulation by different guanylyl cyclases, PDEs, and enzyme modulating drugs (green $=$ key agonistic regulator proteins and cGMP effector proteins; red = key antagonistic regulator proteins, striped green = hydrolyzing cGMP effector proteins; bold, blue letters = drugs approved in clinics and italic blue letters $=$ drugs in clinical development).

NO donor compounds has the longest history but also limitations, including tolerance and lack of efficacy on apo-sGC, as it lacks the NO-binding heme. New targeted strategies circumvent some of these drawbacks. These so-called sGC stimulators or activators target either $\mathrm{Fe}(\mathrm{II})$ heme-containing sGC or apo-sGC, respectively, to enhance cGMP synthesis directly (Figure 2).

\section{sGC stimulators (sGCs)}

The exact binding mechanism and site of sGCs are still unclear. They allosterically sensitize $\mathrm{Fe}$ (II)heme-containing sGC to NO. If levels of endogenous $\mathrm{NO}$ were pathologically diminished, this will result in a mechanism-based "repair" of a physiological cGMP response. If $\mathrm{sGC}$ is maximally activated by physiological NO levels, sGCs that sensitize sGC for NO have by definition no or only a very limited additional effect on cGMP. Importantly, two sGCs have shown therapeutic benefit in recent clinical trials. Riociguat (BAY 63-2521) was the first sGC stimulator to be approved for use in two different forms of pulmonary hypertension, i.e., pulmonary arterial hypertension $(\mathrm{PAH})$ and chronic thromboembolic pulmonary hypertension (CTEPH). Both are cardiovascular disorders with underlying endothelial dysfunction associated with decreased NO bioavailability as well as vascular remodeling. Riociguat is now being clinically evaluated in other forms of pulmonary hypertension, including that associated with hypoxia (NCT00640315) and left heart disease (NCT01065454), and also cystic fibrosis (NCT02170025) and systemic scleroderma (NCT02283762). A second sGC stimulator, vericiguat (BAY 1021189), has passed late-stage phase II (SOCRATRES program) to investigate its efficacy and safety in heart failure (HF) with either reduced or preserved ejection fraction (HFrEF and HFpEF). Both Bayer Healthcare (Berlin, Germany) compounds, riociguat and vericiguat, are based on the leading indazole structure of $\mathrm{YC}-1$, which was the first described sGCs. However, novel classes of sGCs have been recently discovered by Ironwood Pharmaceuticals (Cambridge, MA) and are characterized by a pyrazole-pyrimidine structure. Preclinically, these compounds are antihypertensive and improve heart failure as well as biomarkers of fibrosis and inflammation. IW-1973 is currently in clinical phase Ib for later application in cardiovascular diseases.

\section{sGC activators (sGCa)}

sGCa specifically bind to NO-insensitive, heme-free apo-sGC. ${ }^{4}$ They thereby reactivate oxidized and NO-insensitive enzyme otherwise prone to degradation. Larger sGCa molecules such as cinaciguat (BAY58-2667), but not the smaller ataciguat (HMR1766), occupy the empty heme site and thereby prevent ubiquitination and proteasomal degradation. Apart from activation, this then leads to stabilization and enhanced sGC protein levels. The nomenclature takes no note of these profound differences: sGCs, sGCa, and stabilizing sGCa all have the same INN ending, -ciguat.sGCa have not yet entered late stage clinical development. A clinical phase II trial (COMPOSE program) with cinaciguat in patients with acute decompensated chronic congestive heart failure had to be abrogated due to severe hypotension. The anthranilic acid derivate ataciguat (HMR1766) is now in phase II (NCT02481258) to evaluate therapeutic efficiency in patients with aortic valve calcification.

\section{NATRIURETIC PEPTIDES AND THEIR GC RECEPTORS}

The family of plasma membrane integrated "particulate" quanylate cyclases contains seven members (GC-A to GC-G), of which GC-D and GC-G only exist as pseudogenes in humans. GC-A and GC-B are receptors for different natriuretic peptides (NP).
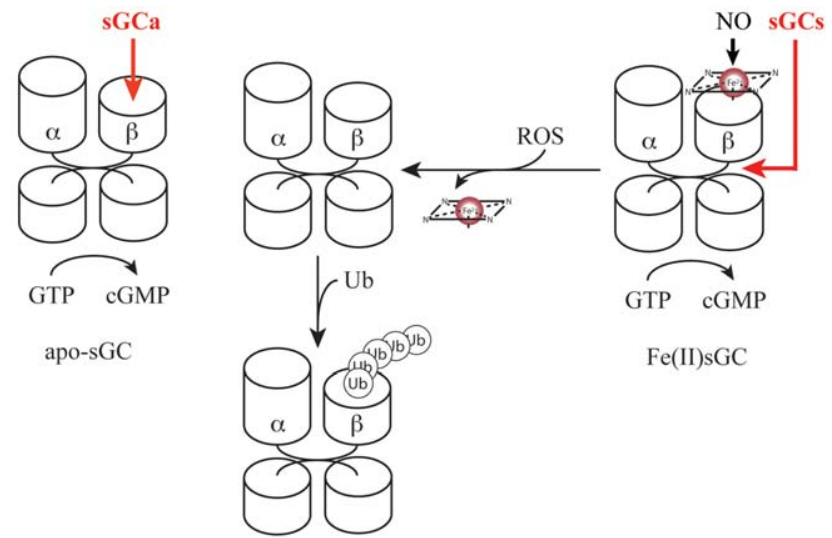

$\mathrm{Fe}(\mathrm{II}) \mathrm{sGC}$

Ubiquitinylated apo-sGC

$$
\begin{gathered}
\downarrow \\
\text { Proteasomal } \\
\text { Degradation }
\end{gathered}
$$

Figure 2 Mechanisms of action of SGC stimulators (sGCs) and activators (sGCa). Fe(II)heme containing sGC (Fe(II)sGC) is the nitric oxide (NO) receptor. sGCs allosterically sensitize Fe(II)sGC so that lower concentrations of NO exert maximal cGMP formation. Upon oxidative stress, SGC's $\mathrm{Fe}(\mathrm{II})$ heme is oxidized to Fe(III) and eventually lost. Heme-free apo-sGC is ubiquinylated and enters proteasomal degradation. SGCa instead binds to the empty heme binding site, preventing ubiquitinylation and thus degradation, and activates apo-sGC to similar $\mathrm{V}_{\max }$ levels as NO-Fe(II)sGC. 
These homodimers consist of an extracellular ligand binding domain which is linked by a single transmembrane domain to an intracellular guanylyl cyclase domain similar to sGC. GC-A synthesizes cGMP upon binding of atrial (ANP) and brain (BNP), whereas GC-B is stimulated by C-type NP (CNP).

For therapeutic purposes, various synthetic peptide activators of GC-A and GC-B have been developed. The ANP analog ularitide has entered a phase III clinical trial (TRUE-AHF, NCT01661634) for acute decompensated heart failure; the recombinant human CNP BMN11, phase II (NCT02055157) for the treatment of achondroplasia in children (GC-B plays a key role in chondrogenesis and bone growth). In addition, the chimeric peptide CD-NP (cenderitide) is now in phase II (NCT02359227) for the treatment of acute heart failure. Besides the difficulties of short biological half-life and poor oral bioavailability, therapeutically optimized NPs, or small molecules targeted to GC-A and/or GC-B, may offer an alternative to sGCs/sGCa to elevate cGMP, most likely with different tissue selectivity and indications.

In addition to supplementing designer NP, compounds, such as sacubitril (AHU-377) block-among other enzymes-the NPdegrading enzyme, neprilysin. Such compounds could offer yet another therapeutic approach in elevating cGMP levels via NPcGMP signaling. A phase III clinical evaluation (PARADIGM; NCT01035255) of LCZ696 vs. enalapril was halted prematurely following an almost 20\% reduction in HF-related hospitalization and cardiovascular (CV) death in the active arm. LCZ696 was fast-tracked by the US Food and Drug Administration (FDA) and licensed for the treatment of heart failure recently.

\section{PDE INHIBITORS (PDEi)}

In addition to enhancing cGMP production for therapeutic benefit, PDEi inhibit cGMP degradation to bring about similar effects. The first and most prominent drug in this class is the PDE5i sildenafil, now used clinically for the treatment of erectile dysfunction and PAH. Different PDE isoforms are present at different subcellular localizations, thereby targeting different cGMP pools and represent a platform for the search for new medical indications. Especially PDE1, PDE2, PDE3, PDE5, and PDE9 have been implicated in different cardiovascular disorders. Proofof-concept has been obtained for PDE5i in erectile dysfunction and pulmonary hypertension, and the acute use of PDE3i in heart failure and thrombosis. The largest therapeutic benefit of PDEi may reside in combination therapies that enhance cGMP production, i.e., sGCs, sGCa, NP, and neprilysin inhibitors. Such combinations would target the cGMP signaling network from different angles and form an example of network pharmacology.

\section{NETWORK PHARMACOLOGY: THE CASE OF CGMP}

NP analogs may not compensate for a loss of sGC function, while vice versa $\mathrm{sGC}$ stimulators may not compensate for a loss of GC-A or GC-B-mediated cGMP production. On top of that, different PDE isoforms can be more specific for either NO- or NP-triggered cGMP production, or both. A logical consequence of this signaling complexity is that in patients with multiple defects in cGMP signaling, cGMP modulators should be combined rather than used as monotherapy. A major hurdle in applying such an approach rationally lies in the lack of biomarkers that are able to assess whether a specific defect in cGMP signaling occurs in a patient.

\section{BIOMARKERS TO IDENTIFY “cGMPOPATHIES" AND STRATIFY PATIENTS}

Currently, the most direct readout of $\mathrm{NO}^{5}$ and NP-cGMP signaling is PKG-mediated phosphorylation of vasodilatorstimulated phosphoprotein (VASP). However, basal VASP phosphorylation per se is too low and variable to identify deregulated cGMP signaling. Filling this gap is necessary to enable patient stratification, and optimize dosing for higher efficacy and safety by providing effective therapeutic/diagnostic (theranostic) couples.

\section{CONFLICT OF INTEREST}

$\mathrm{AH}$ acts on advisory boards of Bayer Healthcare and Novartis.

(c) 2016 American Society for Clinical Pharmacology and Therapeutics

1. Paulus, W.J. \& Tschöpe, C. A novel paradigm for heart failure with preserved ejection fraction: comorbidities drive myocardial dysfunction and remodeling through coronary microvascular endothelial inflammation. J. Am. Coll. Cardiol. 62, 263-271 (2013).

2. Erdmann, J. et al. Dysfunctional nitric oxide signalling increases risk of myocardial infarction. Nature 504, 432-436 (2013).

3. Kirsch, M., Kemp-Harper, B., Weissmann, N., Grimminger, F. \& Schmidt, H.H.H.W. Sildenafil in hypoxic pulmonary hypertension potentiates a compensatory up-regulation of NO-cGMP signaling. FASEB J. 22, 30-40 (2008).

4. Stasch, J.-P. et al. Targeting the heme-oxidized nitric oxide receptor for selective vasodilatation of diseased blood vessels. J. Clin. Invest. 116, 2552-2561 (2006).

5. Ahrens, I. et al. Measuring oxidative burden and predicting pharmacological response in coronary artery disease patients with a novel direct activator of haem-free/oxidised sGC. Atherosclerosis $\mathbf{2 1 8}$, 431-434 (2011). 